\title{
ORTOGRAFIA DA LÍNGUA PORTUGUESA: UMA ANÁLISE EM TEXTOS DE ESTUDANTES DO ENSINO MÉDIO
}

\author{
Valfrido da Silva Nunes ${ }^{1}$
}

\begin{abstract}
Resumo: Este artigo resulta de uma pesquisa desenvolvida com estudantes do ensino médio da rede pública estadual de Pernambuco acerca da ortografia da língua portuguesa. A pesquisa teve como objetivo identificar os equívocos ortográficos mais recorrentes nos textos analisados e classificá-los em regulares e irregulares, conforme a abordagem construtivista da ortografia dentro dos estudos linguísticos (MORAIS, 2007; 2009; 2012). A metodologia consistiu numa análise de corpus, por meio da coleta de 100 (cem) textos de diferentes gêneros jornalísticos produzidos pelos estudantes, e as análises combinam dados quantitativos com um olhar interpretativo. Os resultados evidenciam que, mesmo estando no ensino médio, os estudantes ainda apresentam desvios ortográficos até mesmo típicos da criança em processo de alfabetização.
\end{abstract}

Palavras-chave: Ortografia. Língua Portuguesa. Erros regulares. Erros irregulares.

\section{PORTUGUESE LANGUAGE ORTHOGRAPHY: AN ANALYSIS IN TEXTS PRODUCED BY STUDENTS FROM SECONDARY SCHOOL}

\begin{abstract}
This article results from a research developed with secondary school students of the state public network of Pernambuco, Brazil, about the orthography of the Portuguese language. The aim of this research was to identify the most recurrent orthographic mistakes in the analyzed texts and to classify them into regular and irregular ones, according to the constructivist approach of orthography within linguistic studies (MORAIS, 2007; 2009; 2012). The methodology consisted of a corpus analysis, through the collection of 100 (one hundred) texts of different journalistic genres produced by the students, and the analyzes combine quantitative data with an interpretive look. The results show that, even in secondary school, students still present orthographic deviations that are even typical of children in the literacy process.
\end{abstract}

Keywords: Orthography. Portuguese language. Regular errors. Irregular errors.

1 Doutorando em Linguística (UFAL). Mestre em Linguística (UFAL). Especialista em Programação do Ensino de Língua Portuguesa (UPE). Licenciado em Letras - Português/Inglês (UPE). Professor do Instituto Federal de Pernambuco (IFPE). 


\section{Introduçáo}

O ensino de língua portuguesa para falantes nativos, em seus diversos níveis e modalidades, especialmente em redes públicas, tem por objetivo oportunizar aos alunos o aprimoramento do seu desempenho linguístico-discursivo, tanto no que diz respeito à modalidade oral, quanto à escrita da língua. Entretanto, é bom lembrar que, assim como a fala, a escrita também não é homogênea; logo, cabe perguntar: de qual escrita a escola deve ocupar-se? Para Possenti (1999, p. 33), "o objetivo da escola é ensinar o português padrão, ou, talvez mais exatamente, o de criar condições para que ele seja aprendido. Qualquer outra hipótese é um equívoco, político e pedagógico". Não é nosso objetivo aprofundar essa discussão neste artigo; porém, o que defendemos é que existe uma escrita cuidadosamente planejada, que tem sido denominada escrita padrão ou escrita formal. Dentro desse conjunto maior, o que nos interessa especificamente é o fato de a escrita padrão ser normatizada por convenções rígidas, exigindo um cuidado maior com as questões de cunho ortográfico.

A metodologia da pesquisa consistiu em uma análise de corpus de 100 (cem) textos coletados no ano de 2007 em turmas de primeiro ano do ensino médio de uma escola estadual do interior de Pernambuco. Trata-se de uma investigação que combina dados quantitativos com análises qualitativas. Assim, foram trabalhados cinco gêneros da esfera midiática, tanto do jornalismo informativo (notícia, reportagem), quanto do jornalismo opinativo (editorial, carta do leitor, artigo de opinião), a fim de que o corpus pudesse ser coletado e, a partir daí, passássemos a garimpar os principais problemas ortográficos apresentados pelos alunos.

O aparato teórico da pesquisa advém de diferentes fontes, ligadas a autores provenientes de ramos diversos do conhecimento, a exemplo de Morais (2007; 2009; 2012), Kato (2005), Henriques (2007; 2009), dentre outros. Devido às especificidades do objeto da pesquisa - as dificuldades ortográficas -, o olhar dispensado para ele fundamenta-se, em certo sentido, no paradigma formalista dos estudos da linguagem, por isso não adentramos as questões de ordem textualdiscursiva.

No que diz respeito ao ensino da ortografia, vemos dois extremos que são problemáticos: por um lado, a ortografia foi muitas vezes tratada no ensino tradicional como uma obsessão, por meio da memorização de regras descontextualizadas com fim em si mesmas; por outro lado, em nome de uma pedagogia do texto - e mais recentemente do gênero - mal aplicada, o ensino da ortografia frequentemente é tratado como uma questão menor ou até mesmo dispensável para alguns. Há muitos que defendem o ensino explícito das regras ortográficas, no que diz respeito às regularidades, e outros que adotam uma pedagogia da imersão, justificando que não há necessidade de explicitação de tais regras. A nossa visão coaduna-se com a daqueles que defendem o ensino explícito das regularidades ortográficas do português, deixando os casos de irregularidades para serem resolvidos por outras vias. 
O presente artigo está organizado em três seções: (i) discussão sobre escrita padrão e ortografia, focando a natureza e a história da ortografia portuguesa, bem como uma discussão sobre a noção de erro; (ii) apresentação dos problemas ortográficos regulares encontrados nos textos dos alunos, ou seja, aqueles que podem ser aprendidos por meio de regras que precisam ser ensinadas explicitamente, a fim de que o aluno possa compreendê-las; e (iii) apresentação dos erros irregulares, isto é, aqueles que não podem ser evitados por meio da internalização de uma regra, mas somente por meio da memorização ou da consulta a fontes seguras.

\section{Escrita padráo e ortografia}

Vivemos numa sociedade que faz uso da língua não só para se comunicar, mas também como forma de perpetuação das relações de poder $^{2}$; estamos o tempo todo imersos num mundo letrado, dinâmico, mutável e por isso precisamos ter a compreensão de que a nossa fala e a nossa escrita também refletem essa dinamicidade e flexibilidade, adaptando-se às diversas circunstâncias das nossas interações nas mais diversas esferas da vida social. A língua não é estática e, evidentemente, a escrita e a fala como suas modalidades também não o são. Entretanto, a instituição escolar parece ignorar isso e, infelizmente, as aulas de língua portuguesa muitas vezes tomam o viés da escrita descontextualiza, da "escrita para ninguém", sem haver uma preocupação maior com a escrita significativa, por meio dos gêneros (orais, escritos ou multimodais).

Muitas vezes, é negado ao aluno o direito de usufruir dos diferentes registros que a língua propicia, por meio dos inúmeros gêneros que circulam na sociedade. E nesse sentido que a língua que o aluno fala muitas vezes lhe é apresentada em sala de aula como uma "língua morta", o que desperta nele um sentimento de estrangeiridade ou até mesmo de impotência para refletir sobre a língua que usa, o que talvez seja uma das razões para as repetidas frases que ouvimos: "eu odeio português" ou "português é muito difícill". A bem da verdade, concordamos com a ideia de que "o discurso da escola sobre a língua considera-a como um grande bloco homogêneo; uma entidade uniforme, sem possibilidade de variação" (ANTUNES, 2007, p. 75).

Desse ponto de vista, podemos dizer que interagimos sempre em função do outro e construímos o nosso discurso conforme o contexto onde estamos inseridos, preocupados com o que estamos dizendo, como dizemos e visando a que efeitos. Nesse ponto, a ideia de gênero parece ser fundamental para abarcar essas questões, visto que o léxico e a gramática estão sempre a serviço do texto. Não é sem propósito que "quando falamos (ou escrevemos), tendemos a nos adequar à situação de uso da língua em que nos encontramos: se é uma situação formal, tentaremos usar uma linguagem formal; se é uma situação descontraída, uma linguagem descontraída, e assim por diante" (BAGNO, 2006a, p. 130).

2 A propósito, Nunes (2015) discute o poder da escrita na burocracia estatal, a partir de um gênero específico dessa esfera: o memorando. 
Desfazemos aqui, pois, o mito de que toda variação ocorre na fala e que a escrita é algo imutável. Na verdade, como postula Marcuschi (2010), fala e escrita não são realidades dicotômicas, mas modalidades de realização de uma mesma língua, com muitas semelhanças entre si. A melhor maneira de ver a relação fala/escrita é considerá-las dentro de um continuum tipológico, em que ambas se entrecruzam em maior ou menor proporção. Corroborando as palavras do autor, Kato (2005, p. 30) afirma que "a linguagem escrita não pode ser definida como um conjunto de propriedades formais, invariantes e distintas das da linguagem falada".

Nesse sentido, detendo-nos ao que nos propusemos estudar com mais profundidade - a relação entre ortografia e escrita padrão - defendemos que uma escrita que exige um grau de planejamento mais tenso tende a ser uma escrita devidamente marcada por convenções rígidas. Tais convenções são o "conjunto de regras que determinam a maneira correta de escrever as palavras de uma língua e usar seus sinais de acentuação e pontuação" (BECHARA, 2011, p. 883). Em que pese o caráter normativo desta definição de ortografia, há de se convir que, de fato, o usuário da língua quando escreve não tem o direito de livre escolha para grafar as palavras da língua. Há uma convenção socialmente aceita de que tal palavra escrevese de tal forma, pois a ortografia "é um tipo de saber resultante de uma convenção, de negociação social e que assume um caráter normativo, prescritivo" (MORAIS, 2007, p. 8), daí a sua natureza arbitrária. Não é sem propósito que, na origem, "o termo vem do grego orthographia, palavra formada de orthós, 'correto', 'direito' e grafia, do verbo graphein, 'escrever"” (PROENÇA FILHO, 2009, p. 15).

É verdade também que usuários proficientes da língua escrita podem transgredir as regras ortográficas para atingir determinados efeitos de sentido, mas isso não se torna uma generalização. A despeito disso, que são casos esporádicos em gêneros que permitem tais variações, a escrita bem cuidada, em geral, requer observância ao padrão socialmente convencionado, até mesmo como forma de tornar a comunicação escrita compreensível. Se pudéssemos grafar as palavras a nosso bel-prazer, como nos primórdios da fixação da escrita portuguesa, a confusão seria inevitável.

Quando realizamos esta pesquisa, verificamos que os alunos não demonstravam a competência ortográfica esperada para a série que estavam cursando, problema este ligado ao baixo nível de letramento desses estudantes. Diante disso, observamos que as possíveis causas desse problema tinham suas raízes no desconhecimento das regularidades e irregularidades da convenção escrita, uma vez que os estudantes possivelmente tinham pouco contato com material impresso, realizavam poucas leituras, registravam suas marcas dialetais na escrita, e tinham sido pouco ou mal trabalhados na escola no tocante à questão ortográfica em séries anteriores.

Segundo Morais (2005, p. 70), "a leitura constante de livros, jornais, revistas e outros suportes impressos constitui, portanto, uma espécie de primeiro mandamento para o desenvolvimento da competência ortográfica". As marcas dialetais, por sua vez, constituem-se em mais um obstáculo no processo de escrita, 
visto que seria impossível uma convenção que contemplasse todas as variações de pronúncias existentes na língua (FARACO, 1994, p. 11). É por esse motivo que a ortografia apresenta certa neutralidade em relação às diferentes realizações fonéticas de uma mesma palavra, muito embora se tenha a consciência de que essa neutralidade não é absoluta, porque quando se criou a ortografia portuguesa tomou-se como referência apenas uma variedade da língua, ou seja, a chamada norma culta ou variedade de prestígio.

Discutindo essa questão, Kato (2005, p. 122) sublinha que "para muitos educadores o que causa problemas mais sérios na alfabetização e na pósalfabetização é a distância entre a fala e a norma escrita usada nos textos escolares". Concordamos com o que a autora afirma, no entanto entendemos que a questão tem se tornado cada vez mais grave, pois esses problemas que não são resolvidos na alfabetização estão se perpetuando ao longo do ensino médio e, quiçá, chegando ao ensino superior e à pós-graduação. Com efeito, essa distância a que a autora se refere entre a fala e a norma escrita é bastante acentuada, em virtude dos múltiplos falares regionais num país continental como o Brasil. No tocante a isso, não há muito que se faça, pois se torna inexequível pensar um projeto de reforma ortográfica que contemple todas as variedades linguísticas do português brasileiro. Resta-nos mostrar ao aluno que a escrita em múltiplas instâncias da vida necessita de um padrão, e fornecer os meios para que ele se torne um usuário proficiente da língua escrita, especialmente no registro formal, visto que a informalidade talvez não precise de explicitação nem de mediação.

Em relação à hipótese de que os problemas ortográficos também estão ligados à lacuna deixada pela escola no decorrer dos anos, pode-se dizer que esse não é um problema local, pois "a ortografia é tratada entre nós mais como tema de verificação que de ensino sistemático, a maioria das escolas do país funciona sem planejar o que espera conseguir na promoção da competência ortográfica de seus alunos a cada ano" (MORAIS, 2005, p. 74). Essa citação do autor traz à tona alguns aspectos que merecem ser postos em relevo. O primeiro concerne à relação "verificação" versus "ensino", pois uma coisa é cobrar ortografia de forma mecânica e outra é promover momentos de explicitação e reflexão efetivas da norma ortográfica, principalmente no que diz respeito às regularidades do sistema ortográfico do português. O segundo aspecto tange ao planejamento ou à falta dele. O que vemos nas escolas é quase nada de ensino sistemático da ortografia e, além disso, o pouco que supostamente se ensina não contempla uma progressão curricular que propicie ao aluno avançar, porque geralmente circula-se em torno dos mesmos exercícios mecânicos. Dificilmente parte-se de corpora de textos de alunos, com a finalidade de se fazer um levantamento dos principais erros que os estudantes apresentam para, a partir daí, se ter subsídios empíricos que justifiquem o ensino de tal regra em lugar de outras, visto que o tempo pedagógico é algo relevante quando se trata de planejamento.

No nosso ponto de vista, só assim é possível fazer um planejamento mais autêntico e, ao mesmo tempo, fazer os alunos avançarem, sem perder tempo repetindo o que eles já sabem e focando naquilo que eles realmente apresentam 
maiores dificuldades. Antunes (2007) defende um programa de ensino que: (i) focalize o texto como parte da atividade discursiva; (ii) focalize a frase e (iii) focalize a palavra. Nesse último ponto, ela faz referência às "normas da ortografia oficial". Chama atenção a preocupação da autora em considerar os aspectos da convenção escrita, pois o que a experiência tem nos mostrado é que em muitas escolas o ensino de línguas tem sido bastante "atropelado", sem dar conta do texto, do discurso, do gênero, dos fenômenos linguísticos (gramática e léxico) e muito menos dos traços peculiares da convenção escrita.

\subsection{A natureza da ortografia portuguesa}

Embora a intenção dos estudiosos tenha sido criar um alfabeto que notasse foneticamente a língua, sabemos que isso na prática não acontece, pois a relação letra-som nem sempre é biunívoca. As diferenças geográficas, sociais, etárias, históricas e de classe social são refletidas na língua, que varia e muda. Segundo Kato $(2005$, p. 17), "na verdade, a relação é essencialmente fonêmica, isto é, a escrita procura representar aquilo que é funcionalmente significativo". A autora cita a palavra "descontar" que, ao ser pronunciada, soa mais ou menos como [discontá(r)], como argumento para sustentar que, de fato, a nossa ortografia não tem motivação alfabética.

Kato (2005, p. 17-19), em defesa da ideia de que a ortografia portuguesa é essencialmente fonêmica, elenca cinco motivações que explicam seu ponto de vista. A primeira delas é a motivação fonêmica, em que se neutralizam diferenças fonéticas que existem na fala, mas que não são significativas. É o que ocorre, por exemplo, com as vogais "a" da palavra casa. Enquanto pronunciamos [a] no primeiro caso, dizemos [Ә] no segundo; já em cama as duas vogais "a" realizam-se como sendo o mesmo fonema [Ә]. Nos dois casos, utilizamos o mesmo grafema para notar sons contextualmente determinados, porém não distintivos, os quais reconhecemos como realizações de um mesmo fonema.

A segunda motivação a que a autora se refere é a motivação fonêmica e fonética, que ocorre quando um fonema só tem uma realização possível. É o caso das relações biunívocas. Por exemplo, o "b" realiza-se sempre como [b] no português, seja em posição pré-vocálica como em "bola", seja em posição pós-vocálica, com em "sub-região". Dizemos, pois, que o "b" é fonêmica e foneticamente motivado. Essa relação de biunivocidade é recorrente em parte das consoantes do português como em "p", "t", "d", "f", "v".

A terceira motivação é fonética. Em outras palavras, a representação ortográfica é apenas foneticamente motivada. Ilustra isso a familiar regra do $m$ antes de $p$ e $b$. Palavras como campo/pombo não admitem o $n$ porque [m], [p] e [b] são bilabiais; fenômeno semelhante ocorre em canto/lindo, uma vez que [n], [t] e [d] são linguoalveolares. Para Kato (2005, p. 18), “a representação ortográfica representa, pois, a qualidade de nasalização que precede essas consoantes homorgânicas (de traços semelhantes), quando elas não são distintivas, mas sim determinadas pelo 
contexto". Dito de outra maneira, é como se, nesses casos, os grafemas "m" e " $n$ " representassem o til sobre a vogal anterior.

A quarta motivação abordada pela autora é lexical, pois quando as palavras partilham o mesmo radical, este deve ser grafado de forma invariante. Vejamos os vocábulos: medicina, médico, medicar, medicando, medicinal. Percebemos que o grafema " $\mathrm{c}$ " ora representa o fonema $[\mathrm{k}]$, ora representa o fonema [s]. Caso semelhante ocorre com sal, saleiro, salinidade, salgado, cuja pronúncia da letra "l" varia como [1] e como [w], esta quando em posição final de sílaba. Nesses casos, o radical da palavra "teria praticamente o estatuto de um ideograma na leitura" (KATO, 2005, p. 18). Contudo, como nem toda palavra grafada com "l" em posição final de sílaba forma uma família (covil, por exemplo), a ortografia nesse caso pode se justificar pela motivação fonêmica, recorrendo-se à motivação lexical como uma estratégia pedagógica.

A quinta motivação é de natureza diacrônica, ou seja, em alguns casos só podemos explicar a representação ortográfica se recorrermos à história da língua. Nesse caso, a razão é etimológica. É com base nisso que aceitamos o (não) uso do "h" inicial, desnecessário do ponto de vista fonético-fonológico, em palavras como homem e ônibus, visto que somente a primeira tinha o " $\mathrm{h}$ " na língua original (hominem, em latim). No dizer de Kato (2005, p. 19), "a língua oral muda e a escrita é conservadora, o que acarreta um afastamento gradativo entre as duas. Quando a motivação vai deixando de existir, o que resulta é um misto de relações motivadas e arbitrárias".

Dado o exposto, é possível perceber que a normatização ortográfica do português é um sistema complexo, que vai muito além da relação som/letra, o que implica reiterar que a escrita do português é essencialmente fonêmica, visto que procura neutralizar diferenças fonéticas que existem na fala, mas que não são significativas, reproduzindo apenas as diferenças fonéticas distintivas. Por outro lado, convém ressaltar a natureza relativamente ideográfica da escrita, uma vez que muitas regularidades do sistema ortográfico são ditadas pela coerência lexical, sem esquecer também o princípio da arbitrariedade, se se olhar a língua do ponto de vista sincrônico. Como disse Normand (2009, p. 46), "um locutor, com efeito, ignora o passado de sua língua e, sobretudo, seus parentescos mais ou menos longínquos com outras línguas; ignora até mesmo as regras que ele aplica, mas sabe aplicá-las". A propósito do passado das línguas, discutamos resumidamente as várias fases por que passou a ortografia portuguesa até os nossos dias.

\subsection{Periodizaçáo histórica da ortografia portuguesa}

Torna-se pertinente afirmar que nem sempre a ortografia portuguesa foi como a que usamos hoje, pois ela é fixada por meio de decretos, o que justifica as possibilidades de alterações sempre que se fizerem necessárias. Lançando um olhar sobre a história das convenções da língua portuguesa, Morais (2005) afirma que nem sempre existiu ortografia. Diferentemente de outras línguas neolatinas - como o espanhol e o francês, que fixaram suas ortografias antes do século XIX 
-, o português só teve suas normas ortográficas instituídas na primeira metade do século XX, primeiramente em Portugal, depois no Brasil. Muitas e diferentes razões são apontadas para esse retardamento, tais como fatores de ordem social e política, dentre eles: a universalização da escolaridade obrigatória, a difusão do livro e o avanço dos meios de comunicação, que contribuíram significativamente para a instituição das normas ortográficas.

De fato, a questão da escolarização é fundamental nesse processo, porque, nesses casos, o ensino e a prática da escrita constituem-se em forças de unificação que contribuem para o estabelecimento de determinada forma de escrever. Um ensino precário não colabora com o processo de implantação de mudanças ortográficas, tal como tem acontecido com a maior parte dos países africanos de expressão portuguesa até o momento, no que se refere à implantação do Novo Acordo Ortográfico da Língua Portuguesa. O mercado editorial também tem um papel relevante na consolidação da escrita, por se constituir como um poderoso agente disseminador da cultura escrita, numa sociedade grafocêntrica como a nossa. A par disso, teceremos algumas considerações acerca da periodização histórica da ortografia portuguesa, baseados em Henriques $(2007$; 2009), para quem a ortografia portuguesa apresenta três momentos distintos: fonético, pseudoetimológico e histórico-científico.

$\mathrm{O}$ período fonético coincide com a chamada fase arcaica da língua portuguesa, que se estende desde 1196 até o final do século XV. Segundo este mesmo autor, o marco inicial deste período está relacionado à data provável de uma cantiga de maldizer de João Soares de Paia contra o rei Navarra - Ora faz ost' o senhor de Navarra -, considerada o primeiro texto datado e escrito em língua portuguesa. Nessa época, não havia uma preocupação em escrever de acordo com a origem das palavras, mas tomava-se como único critério a maneira de pronunciá-las. Daí depreender-se que se tratava de uma verdadeira "torre de Babel", pois a pronúncia é algo impossível de se padronizar. Desse modo, por falta de sistematização, um mesmo sinal gráfico podia representar diversos sons num mesmo texto. É o caso do "h" que podia representar a tonicidade de vogal ( $h e=$ é), a existência de um hiato $($ trahedor $=$ traidor $)$ o fonema /i/ (sabha $=$ sabia) ou ainda figurar sem função definida (bua = uma; bidade $=$ idade) e assim por diante.

O perído pseudoetimológico, inaugurado no Renascimento, inicia-se em 1489 e vai até os primeiros anos do século XX. Ainda conforme Henriques (2007), o ano inicial desse período data do primeiro documento impresso em língua portuguesa, o Tratado de Confissom, que já mostra as características que predominariam na ortografia a partir de século XVI. Influenciados pelos estudos humanísticos, os autores deste período tinham a pretensão de imitar os clássicos gregos e latinos. Como não tinham um conhecimento linguístico sólido, propunham uma ortografia cheia de complicações sem muita utilidade, contrária aos princípios de evolução da língua. É desse período o excessivo uso do "ph" (philosophia, nynpha), do "th" (theatro, Athenas), do "rh" (rhombo, rheumatismo), do "ch" com som de [k] (chimica, cherubim, technico) e do "y" (martyr, pyramide) para a transcrição de palavras cuja origem era grega. O mesmo ocorreu com a duplicação de consoantes intervocálicas 
(approximar, abbade, gatto, bocca). Eis a razão que justifica seu caráter relativamente "falso", uma vez que, sob o pretexto de ser etimológica, tal ortografia estava repleta de formas equivocadas, contrariando a etimologia e a evolução da língua.

O período bistórico-científico inicia-se com a adoção da chamada "nova ortografia"; começa em 1904 (ano da publicação de Ortografia Nacional, do português Gonçalves Viana) e vai até os dias atuais. A partir desse período, passou-se a ter uma nova visão a respeito desse assunto; desta vez, os estudos têm base científica. Vários estudiosos portugueses e brasileiros participaram desses estudos, através de acordo firmado entre a Academia das Ciências de Lisboa (ACL) e a Academia Brasileira de Letras (ABL). Este é, até hoje, um período de muitos dilemas, pois firmar uma ortografia unificada para todos os países da comunidade lusofônica ${ }^{3}$ - Portugal, Brasil, Angola, Moçambique, Guiné Bissau, Guiné Equatorial, Cabo Verde, São Tomé e Príncipe e Timor Leste - envolve questões políticas, econômicas e culturais que vão além da língua portuguesa, a sétima mais falada entre as inúmeras existentes no mundo ${ }^{4}$. Cabe lembrar que a discussão atual no mundo da lusofonia não diz respeito a uma reforma ortográfica, mas a um acordo que, segundo o Instituto Antônio Houaiss (2009, p. 24) visa a "fixar e restringir as diferenças de escrita atualmente existentes entre os falantes da língua" e, ao mesmo tempo, "ensejar uma comunidade que se constitua num grupo linguístico expressivo, capaz de ampliar seu prestígio junto aos organismos internacionais".

No tocante a isso, Kato (2005) tece algumas considerações afirmando que a questão da reforma ortográfica entre nós é polêmica, visto que há uma diversidade dialetal. A autora deixa claro também que uma reforma que só levasse em conta a relação biunívoca fala/escrita seria desastrosa, pois há muita regularidade na língua ditada pela coerência lexical. De fato, vemos que a questão ortográfica não é um assunto à margem ou que deva ser considerado inferior, uma vez que, enquanto convenção humana, estará sempre aberta a novas alterações e mudanças. Portanto, defendemos que se devam colocar em prática as mudanças na ortografia advindas do acordo de 1990, que não são tantas assim (em torno de $0,45 \%$, no caso do Brasil), para que, num futuro distante, se possa aprimorá-las cada vez mais, no intuito de fortalecer a língua portuguesa no cenário internacional; caso contrário, continuará a ser uma mesma língua com duas ortografias oficiais, o que é, em certo sentido, desnecessário.

\subsection{Discutindo a noçáo de erro ortográfico}

Nesse contexto, torna-se premente repensar a noção de erro, quando se trata de língua/linguagem. Consiste em não confundir erro ortográfico com "erro de

3 Informações constantes do portal virtual da Comunidade dos Países de Língua Portuguesa (CPLP). Disponível em: <https://www.cplp.org/id-2597.aspx> Acesso em: 22 jul. 2017.

4 Além dos Estados-membros da CPLP, onde a língua portuguesa é oficial, o português é falado em outras regiões do mundo, a exemplo de: Goa (India), Macau (China), Malaca (Malásia), terras por onde os portugueses circularam à época da expansão ultramarina europeia. 
português", já que, do ponto de vista científico, este não existe, pois estaria ligado à quebra da estrutura sintática da gramática internalizada através de construções agramaticais - que todo falante da língua, independentemente de origem, idade, sexo, classe social, escolarização não comete -, enquanto aquele diz respeito aos desvios ortográficos, ou seja, às hipóteses levantadas pelo aluno ao tentar grafar corretamente um vocábulo, mais precisamente quando a relação fonema/letra extrapola o âmbito da biunivocidade.

Nessa perspectiva, o equivocado "erro de português" não passa de uma variação, dentre tantas outras, da norma que a tradição prescritiva considera o dialeto de prestígio. Os Parâmetros Curriculares Nacionais do Ensino Médio (PCNEM), enquanto documento que norteia a educação no país e, evidentemente, o ensino da língua materna, corroboram essa ideia, ao destacar que "quando se considera a pluralidade de discursos proporcionados por essas variedades, nas modalidades oral e escrita, torna-se pertinente o questionamento de rótulos como certo e errado" (BRASIL, 2002, p. 75). Desse modo, ressaltamos que o conceito de "erro", em oposição ao que é "certo", é resultante de um processo histórico e ideológico; por isso, "é importante lembrarmos que essas duas noções são frutos de convenções humanas, nem sempre utilizadas a serviço da maioria, mas, muitas vezes, manipuladas para atender aos interesses de uma determinada classe social" (ZORAYA; LIMA, 2007, p. 73).

Todavia, é importante entender que, muito além da nomenclatura, é preciso refletir sobre a prática. Assim, não basta somente dizer que o erro de ortografia que existe, de fato, uma vez que ortografia é convenção, acordo estabelecido por lei - é um indício das hipóteses levantadas pelo aluno para tentar escrever segundo o padrão ortográfico da língua, mas deve-se tomá-lo como ponto de partida para ajudar esse aluno a aprimorar a sua habilidade de escrever. Acerca disso, Morais (2007, p. 17) explicita que "a substituição de nomes ('erro' por 'hipótese' etc.) não garante um ensino que de fato auxilie o aprendiz apropriar-se das propriedades regulares e irregulares da forma de escrever que ele tem que... reproduzir". Portanto, substituir o vocábulo "erro" por "inadequações", "violações", "hipóteses" ou "desvios" simplesmente como eufemismos sem redirecionar a prática da sala de aula é, a nosso ver, somente mais um modismo. A nossa posição, neste artigo, é a de que o erro de ortografia existe, uma vez que se trata de uma convenção social, imposta legalmente. Passemos, portanto, a discutir os principais erros ortográficos encontrados nos textos produzidos pelos alunos.

\section{Panorama dos problemas ortográficos encontrados nos textos dos alunos}

Entendemos por regularidade o fenômeno em que podemos prever a forma correta de se escrever a palavra sem nunca a termos visto, a partir de um princípio gerativo, isto é, uma regra que se aplica a várias ou todas as palavras da língua nas quais aparece a dificuldade em questão. Segundo Morais (2005), tal princípio pode ocorrer de três formas: (i) pela relação letra/som - que ele também denomina de regularidades diretas - ("dapete" em vez de "tapete", "bato" em vez de "pato"); (ii) 
pelo contexto da palavra ("serote" em vez de "serrote", "banbu" em vez de "bambu") e (iii) pela relação morfológico-gramatical ("estudol" em vez de "estudo $u$ ", "beberão" (no tempo passado) em vez de "beberam"). Por outro lado, as dificuldades irregulares não podem ser explicadas por meio de uma regra, visto que são justificadas pela tradição do uso ou pela etimologia da palavra, exigindo que o aprendiz memorize a forma correta da escrita ou recorra a um dicionário. Do ponto de vista didáticopedagógico, não há muito que explicitar ao aluno, por isso mesmo a consulta a fontes de referências e a textos bem escritos em língua padrão, aliados a uma prática efetiva de produção de textos, parecem ser o melhor caminho para minimizar tais problemas. A tabela a seguir ilustra os principais erros cometidos pelos estudantes no corpus analisado.

Tab. 1 - Categorização de erros regulares e irregulares encontrados em textos de alunos do ensino médio

\begin{tabular}{|c|c|}
\hline PROBLEMA & $(\%)$ \\
\hline Fonema /s/ & 19,3 \\
\hline Fenômeno da nasalização & 14,8 \\
\hline Marcas da oralidade & 13,2 \\
\hline Ausência de " $\mathrm{r}$ " no infinitivo & 12,6 \\
\hline Acentuação gráfica & 8,7 \\
\hline Letras "e", “i”, “o", "u” em sílabas átonas que não estão no final das palavras & 7,0 \\
\hline Fonema /z/ & 5,9 \\
\hline Letras "l", "u", "o" no final de palavras representando o fonema /w/ & 3,1 \\
\hline Letra "h" no início de palavras & 2,8 \\
\hline Par mínimo & 2,5 \\
\hline Fenômeno da monotongação & 1,7 \\
\hline Letras "e", "i" no final de palavras representando o fonema /i/ & 1,4 \\
\hline Emprego da letra "x" & 1,1 \\
\hline Verbos na terceira pessoa do pretérito perfeito do indicativo & 1,1 \\
\hline Emprego do hífen em casos de ênclise & 1,1 \\
\hline Verbos no pretérito imperfeito do subjuntivo & 1,1 \\
\hline Fenômeno da assimilação & 0,8 \\
\hline Fenômeno da epêntese & 0,6 \\
\hline Fonema /R/ & 0,6 \\
\hline Fonema /g/ & 0,3 \\
\hline Fonema /ž/ & 0,3 \\
\hline
\end{tabular}

Fonte: Acervo da pesquisa

A tabela acima revela um dado interessante: dos quatro problemas mais recorrentes nos textos dos estudantes, dois deles dizem respeito a erros regulares (o fenômeno da nasalização e a ausência de " $\mathrm{r}$ " no infinitivo), ou seja, àqueles cujas regras podem ser explicitadas aos estudantes, de modo que eles a internalizem e 
não voltem a cometê-los novamente. Melhor dizendo, na verdade esses alunos já deveriam ter conhecimento dessas regras, caso houvesse um planejamento sistemático e eficaz da questão ortográfica na escola, desde as séries iniciais. O desafio que se impõe, portanto, é buscar formas de entender esses erros e tentar ajudar os alunos a compreendê-los para evitá-los, mesmo que um tanto tardiamente.

\subsection{Regularidades do sistema ortográfico}

Nesta seção, trataremos especificamente dos erros regulares encontrados nos textos dos estudantes. Defendemos que é possível ensinar ortografia aos alunos, desde que se trate de uma regularidade do sistema. Como Morais (2012, p. 161) já havia frisado, "nos casos das restrições regulares, em que há um princípio gerador que pode ser aplicado a muitas palavras da língua, o aluno vai aprender compreendendo". Portanto, deixar que os alunos aprendam de forma espontânea, talvez seja um desserviço ao ensino de língua materna, já tão precário nas escolas públicas, se considerarmos a conjuntura histórica, cultural e educacional do nosso país. A seguir, exemplificaremos com os dados do corpus os principais casos de erros regulares observados.

\subsubsection{Ausência de " $r$ " no infinitivo}

O infinitivo é marcado morfologicamente pela desinência " $r$ ", designando as conjugações verbais ("amar"; "vender", "partir"). Vejamos como o aluno usa essa forma nominal do verbo:

[1] “- Estou escrevendo, para o jornal, para fala um fato (...) estou mandando essa carta para o senhor publica no jornal..."

Para Morais (2005, p. 42), que classifica esse caso como uma regularidade morfológico-gramatical presente nas flexões verbais, "todos os infinitivos terminam com R ('cantar', 'beber', 'partir'), embora esse R não seja pronunciado em muitas regiões do nosso país". Isso nos leva a inferir que tal erro ocorre porque essa desinência do infinitivo não é pronunciada na variante falada pelos alunos, o que explica o emprego de "fala" para "falar" e "publica" para "publicar" no texto do aluno. Este problema, com 45 (quarenta e cinco) ocorrências, corresponde a $12,6 \%$ dos erros analisados, conforme vimos na tabela anterior, ou seja, o quarto fenômeno com maior incidência no corpus. A ocorrência desses equívocos convida o professor a discutir com os estudantes a questão da tonicidade das palavras. Tomando [1] como exemplo, quando se escreve a palavra "fala", a tonicidade recai sobre a primeira sílaba, já que se trata de uma paroxítona. Diferentemente, quando se grafa "falar", há um deslocamento da tonicidade, pois a sílaba mais forte é a última, ilustrando um caso de oxítona. Evidente que a língua possibilita ambas as ocorrências ("fala" e "falar"); entretanto, os usos são diferentes para cada um dos casos. 


\subsubsection{Fenômeno da nasalizaçáo}

Segundo Morais (2005, p. 38), o fenômeno da nasalização é um caso de regularidade contextual, para quem a escrita das vogais e ditongos nasais constitui uma grande fonte de dificuldades para os aprendizes. Ele explica que há cinco modos de marcar a nasalidade na escrita do português: (i) usando-se o " $\mathrm{m}$ " em posição final de sílaba ("bambu"); (ii) usando-se o " $n$ " também em posição final de sílaba ("banda"); (iii) empregando-se o til ( ) ("pão"); (iv) usando-se o dígrafo "nh" ("minha”); e (v) por contiguidade, ou seja, quando a sílaba seguinte já começa com uma consoante nasal ("cama", cana"). Vejamos nos exemplos abaixo como algumas dessas marcações aparecem nos textos analisados.

\subsubsection{Emprego de " $m$ " e " $n$ " em posiçáo final de sílaba}

Produzindo um gênero jornalístico, o aluno comete o seguinte equívoco ortográfico:

[2] “... o avião ia com destino a Recife capital de Pernanbuco e morrerão mais de 180 pessoas (...)"

Percebemos que o emprego das letras " $m$ " e " $n$ " como nasalizadoras da vogal anterior nestes contextos está inadequado, pois antes dos fonemas bilabiais $/ \mathrm{p} / \mathrm{e} / \mathrm{b} / \mathrm{usa}$-se a letra "m", porém, diante dos demais fonemas, emprega-se a letra "n" para marcar a nasalização da vogal. $\mathrm{Na}$ verdade, o que há nestes casos é uma motivação de natureza fonética. De fato, "a representação ortográfica representa, pois, a qualidade de nasalização que precede essas consoantes homorgânicas (de traços semelhantes), quando elas não são distintivas, mas sim determinadas pelo contexto" (KATO, 2005, p. 18). A bem da verdade, esse olhar que procura entender a razão que motiva os erros ortográficos cometidos pelos estudantes traz uma contribuição relevante para esclarecer uma regra aparentemente banal: o emprego do "m" antes de "p" e "b". Regras obsoletas, focadas no "decoreba", tais como: "A mamãe não se separa do papai e do bebê", comumente usada por professores, especialmente alfabetizadores, para fixar a regra, não enfrentam o problema do ponto de vista do conhecimento linguístico produzido, tornando-se artificial.

\subsubsection{Emprego do til ( $)$}

Tomemos o exemplo que segue:

[3] “... no passado todos eram amigos o sol era amigo do mar a chuva era amigo da lua e assim todos se unirão, tinha veram, inverno, primavera...”

A ocorrência de "unirão" em vez de "uniram" traz à tona uma regularidade do sistema ortográfico do português. Sabe-se que a desinência "-rão" refere-se ao verbo na terceira pessoa do plural do futuro do presente do indicativo, enquanto o verbo na terceira pessoa no pretérito perfeito deve apresentar a desinência "-ram". Dessa forma, a explicação dá-se pelas regularidades morfológico-gramaticais, uma vez que, caso o aluno domine a estrutura morfológica dos verbos, e compreenda 
a noção de temporalidade, possivelmente não cometerá tal equívoco. Ainda em [3], chama atenção o fato de o estudante grafar o substantivo "veram" ("verão"), fazendo uso de um recurso disponível na língua para marcar a nasalização: a terminação "-am"; entretanto, não se trata de um verbo, mas sim de um substantivo. Em geral, os substantivos como nasalização na sílaba final escrevem-se com "-ão", recurso também usado quando são postos no grau aumentativo.

\subsubsection{Ausência do marcador de nasalizaçáo}

Solicitado a escrever uma notícia, o aluno - que produz uma narrativa com diálogos sobre um assalto, não atendendo as especificidades do gênero - em certo momento faz a seguinte construção sintática:

[4] “... avia gente tentando derrubar a sua porta da cozia, o ladrão, derrubou, a porta...”

Vemos, pois, que o aluno não usou o marcador de nasalização que seria o dígrafo "nh", visto que ele nem sempre é pronunciado, conforme ilustra Morais (2005, p. 38), ao afirmar que "em diferentes regiões do Brasil, palavras como 'minha' e 'galinha' são de fato pronunciadas /mĩa/ e /galĩa/, de modo que a vogal anterior ao dígrafo é nasalizada e ele não é pronunciado".

\subsubsection{Presença desnecessária do marcador de nasalizaçáo}

Há casos em que o marcador de nasalização é desnecessário, como em:

[5] “... na maioria das vezes os jovens não tenhe trabalho, então passa a ter o consumo de drogas"

Percebemos que em [5] ocorre o inverso do que citamos em [4], isto é, o aluno reproduz na escrita um suposto dígrafo que aparece na oralidade, quando grafa o verbo flexionado na terceira pessoa do plural do presente do indicativo, que deveria ser grafado com a forma "têm". É provável que esse fato tenha a ver com uma variação na pronúncia desse verbo na região onde ele vive. Verificamos que o fenômeno da nasalização apresenta muita dificuldade para os estudantes, totalizando 53 (cinquenta e três) ocorrências, as quais representam 14,8\% dos erros encontrados, o que nos leva a concluir que este é o segundo tipo de erro mais frequente nos textos analisados.

\subsubsection{Verbo no pretérito imperfeito do subjuntivo}

Acerca desse fenômeno, tomemos como ponto de partida o excerto abaixo:

[6] “... gostaria que o prefeito tomaci as providências já asfaltaram dodas as outras ruas menos a que eu moro no imverno não se dar nem pra pasar e no verão a poeira emcomoda deicha as crianças gripadas. então gostaria que a prefeitura asfaltace a rua porque não estamos aguentando mas." 
Além de outros problemas que retomaremos adiante, vemos que o uso do verbo no pretérito imperfeito do modo subjuntivo está grafado de forma incorreta de acordo com a norma ortográfica da língua portuguesa, porque todas as flexões desse tempo/modo verbal grafam-se com "ss". Assim, ressaltamos que esse é mais um caso de regularidade morfológico-gramatical que o aluno teria que dominar para escrever conforme o registro padrão da língua escrita. Esse caso, que apareceu em pequena proporção, corresponde a apenas 4 (quatro) ocorrências, que equivalem a $1,1 \%$ dos dados analisados.

\subsubsection{Par mínimo}

Para Couto (1997, p. 65), um "par mínimo" (minimalpair) constitui-se em "um par de palavras que se distinguem por um único segmento". Tal fenômeno explicase pelo fato de, embora serem letras que correspondem a um único som (relação biunívoca), elas apresentarem semelhanças porque são produzidas expelindo-se o ar do mesmo modo, no mesmo ponto de articulação, diferindo-se apenas pelo fato de uma ser surda e a outra sonora. Vejamos como esse fenômeno manifesta-se no texto do aluno:

[7] “...costaria de parapenizar todos os puliticos que si elegeral nessa eleição no Estado de pernambuco..."

Os termos em negrito revelam a confusão que o estudante faz, quando troca um fonema da língua por outro com quem mantém alguma semelhança sonora. É o caso dos pares "c"/ "g" em "costaria" ("gostaria") e "p"/"b" em "parapenizar" ("parabenizar"). A bem dizer, "essas trocas se devem ao fato de os sons em questão serem muito parecidos em sua realização no aparelho fonador" (MORAIS, 2009, p. 37). Esse fenômeno, que é considerado como um caso de regularidade direta, apareceu em pequenas proporções. Verificamos 9 (nove) ocorrências, o que equivale a $2,5 \%$ dos dados analisados.

\subsubsection{Letras "l"/“u"/“o" no final de palavras representando o fonema /w/}

Vejamos um exemplo retirado do corpus da pesquisa.

[8] “... você com sua fé, gosto de vencer, estudol muito e chegou com confiança e determinação e conseguiu passar na prova”.

Nesse excerto, temos um exemplo de regularidade morfológico-gramatical presente nas flexões verbais. Aqui o escrevente não tem a consciência de que todos os verbos na terceira pessoa (incluindo também as flexões de $2^{\mathrm{a}}$ pessoa com o pronome "você"), no pretérito perfeito do indicativo se escrevem com "u" no final. A prova legítima disso é que em [8] o estudante empregou o verbo "chegou" de forma correta, na mesma frase. Por outro lado, essa dúvida não acontece apenas com os verbos, pois aparece em outras classes gramaticais, contexto em que nem sempre é fácil fazer o emprego do grafema adequado, tal como ocorre no exemplo abaixo: 
[9] "No pais em que vivemos, uma vaga no mercado de trabalho ceja da qual for e muito dificio, seja em capitais ou em cidades pequenas...”

A troca da letra "l" pelo "o", representando o fonema /w/, no caso do adjetivo "difícil", não representa uma regularidade do sistema ortográfico, visto que uma palavra também paroxítona terminada em ditongo como "sacrifício" escrevese, de fato, com "o" final. No meio das palavras, a confusão também aparece:

[10] “... hoje no Brasil, as drogas é um dos casos mais emportante no país, pois é onde almenta o sofrimento e a preocupação dos pais, a maioria dos jovens de hoje, já chegam a adolecência praticamente dependente das drogas".

Pelo visto, não há aqui uma regra que explique esse uso inadequado da palavra "almenta" ("aumenta"), senão pela questão fonética. Erros ortográficos dessa natureza não são tão comuns, pois identificamos em 11 (onze) ocasiões, perfazendo 3,1\% dos dados analisados.

\subsubsection{Acentuaçáo gráfica}

A questão da acentuação gráfica, que é uma convenção, pode ser aprendida através das regras que a regem, por isso a consideramos como uma regularidade do sistema ortográfico do português. No entanto, neste artigo, preocupamo-nos em analisar aqueles erros, cujo emprego inadequado do acento implica mudança de sentido, conforme mostraremos abaixo, no gênero carta do leitor, produzido por um aluno sobre o desvio de verbas da educação:

[11] “... A educação em nosso pais está em situação critica pois a verba que vem para escola está sendo desviada pelos politicos, eles não fazem nada para melhorar, porém querem ser eleitos".

É certo que o contexto faz com que entendamos o significado dos termos em negrito, no entanto, se fôssemos analisá-los isoladamente, somente o sinal diacrítico seria capaz de fazer a distinção semântica, pois o vocábulo "pais" designa os genitores de uma família, enquanto "país" nomeia um lugar de origem, nacionalidade, sendo esta última a intenção do autor do texto em análise. Semelhantemente, "critica" ("crítica"), que nesse contexto é um adjetivo que caracteriza o substantivo "situação", necessita do acento gráfico, caso contrário, significa que o verbo "criticar" está flexionado na terceira pessoa do singular do presente do indicativo. Cumpre salientar ainda que a diferença entre esses pares dá-se também pela tonicidade, conforme mostram as sílabas tônicas destacadas em negrito ("país"/"pais"). Vale salientar que nem sempre os desvios de acentuação causam mudanças semânticas, porém resultam em discordância da norma padrão, causando ainda estranheza na pronúncia, é o que ocorre com a palavra "politicos" ("políticos"), que gramaticalmente deve ser acentuada, por ser uma proparoxítona. Verificamos no corpus que os equívocos relacionados à acentuação gráfica, além de envolver casos em que o acento não é colocado, dizem respeito também ao uso desnecessário dele, numa tentativa de marcar os sons abertos ou fechados. As violações referentes ao uso desses diacríticos são comuns nos textos. Não é 
por acaso que elas representam $8,7 \%$ da dos dados analisados, uma vez que identificamos 31 (trinta e uma) ocorrências.

\subsubsection{Verbos na terceira pessoa do pretérito perfeito do indicativo}

Observemos esta ocorrência, em que o verbo na terceira pessoa do pretérito perfeito do indicativo foi escrito de forma equivocada:

[12] “... Carla esto escrevendo esta carta te parabenizando por sua maravilhosa prova do vestibular...”

O termo em destaque ilustra uma desobediência à morfologia dos verbos, uma vez que todas as formas da terceira pessoa do singular no passado (perfeito do indicativo) se escrevem com " $u$ " no final. Possivelmente, a ausência do "u" final também se explica por razões fonéticas, pois esse "u" praticamente é emitido com rapidez ou não é pronunciado. Verificamos que houve apenas 4 (quatro) ocorrências para este fenômeno, o que representa $1,1 \%$ dos erros identificados.

\subsubsection{Fonema / $R /$}

Vejamos o exemplo abaixo, em que a representação gráfica do fonema /R/ foi empregada equivocadamente:

[13] “... gefersson e pedro saíram corendo e deixaram Leandro para trás como os dois iam na frente eles viram que vinha um carro mais que dava tempo para atravessar(...) o carro acabou pegando ele em cheio vindo a morrer na hora."

No fragmento acima, constatamos que o aluno confundiu-se, pois a letra "r" pode representar tanto o fonema / R/ quanto o fonema /r/, de acordo com o contexto da palavra. Nesses casos, a presença de apenas um " $r$ " na palavra "corendo" possibilitaria uma pronúncia do " $\mathrm{r}$ " com som vibrante, o que não parece ser o propósito de quem escreveu. Reconhecemos aqui que se trata de casos de regularidade contextual, visto que a letra " $\mathrm{r}$ " entre duas vogais tem o som de /r/, exigindo para o som de /R/ a duplicação da consoante " $\mathrm{r}$ ". Pelas nossas análises, erros dessa natureza não são tão frequentes, pois ocorreram apenas 2 (duas) vezes, correspondendo a $0,6 \%$ no gráfico.

\subsubsection{Emprego do hífen em casos de ênclise}

$\mathrm{Na}$ língua portuguesa, os casos de ênclise, ou seja, quando o pronome oblíquo átono deve ser colocado depois do verbo, requerem o uso do hífen para ligar o verbo ao pronome, tornando-os uma unidade semântica. Na verdade, a ênclise é pouco usada no português do Brasil, que tem se tornado uma língua proclítica por excelência. Mesmo assim, há casos em que a ênclise deve ser utilizada, especialmente em textos escritos. Vejamos uma ocorrência, em que a regra do emprego do hífen não foi obedecida. 
[14] "Prineiro conhecemos [a droga] talvez en uma festa depois pegamos e ficamos vidrados nela, não consegue esquecê-la quer tela sempre..."

O uso do hífen, quer queira quer não, é pautado por regras gramaticais, o que sinaliza que o desconhecimento delas é o que ocasiona esses erros. Nesse caso, o aluno não segue a regra que diz que as flexões verbais seguidas de pronomes oblíquos átonos devem ser separadas por hífen; a formas correta do termo em negrito é, pois, "tê-la". Curiosamente, a ausência do hífen gerou uma nova palavra: "tela" (suporte físico), caso fosse desvinculada do contexto. Durante a pesquisa, não foi encontrado nenhum caso que envolve o uso do hífen em substantivos e adjetivos compostos. A ausência do hífen em casos de colocação pronominal na forma de ênclise foi encontrada em pequena proporção, totalizando 4 (quatro) ocorrências, o que tem uma representatividade de 1,1\% dos dados analisados.

\subsubsection{Fonema $/ g /$}

Uma notícia, produzida em contexto de sala de aula, cujo tema foi a violência nas ruas, foi escrita da seguinte forma por um aluno:

[15] “... Os bandidos estavam armados e drogados os elementos obrigaram as pessoas sairem do carro elas ficaram nervoza mas os bamdidos não machucaram ningem"

Esse caso, que trata de uma regularidade contextual, demonstra que o aluno equivocou-se ao não usar o dígrafo "gu" para representar o som $/ \mathrm{g} /$, pois numa leitura literal da palavra em negrito, a letra "g" representaria o fonema / $/ \check{z} /$. Para Morais (2005, p. 40), "em alguns casos as regras se aplicam a todas as palavras da língua nas quais a letra aparece, independentemente de estar no princípio, no meio ou no fim da palavra (é o caso da disputa entre G ou GU)". Classificamos esse caso como raro, tendo em vista que ele foi identificado uma única vez, equivalendo a $0,3 \%$ dos dados analisados.

\subsubsection{Letras " $e$ ", “ $i$ " no final de palavras representando o fonema / $i$ /}

Outro caso de regularidade do sistema ortográfico da língua portuguesa diz respeito ao fato de haver uma disputa entre as letras "e" e "i" para representar o fonema /i/ no final de palavras; no entanto, apenas uma delas ("e") deve ser empregada com regularidade, quando a última sílaba da palavra é átona. Observemos o exemplo:

[16] “... Seu José e sua fámilia estava em casa ai Seu José pessou e dissi para sua esposa Maria hoji nós vamos para a praia arrumi as malas Maria falou José...”

Ocorre nas palavras destacadas um fenômeno fonético-fonológico, no qual as letras "e" e "i" competem entre si para representar o fonema /i/. Isso acontece porque a sílaba final da palavra é átona, provocando uma neutralização fonológica. $\mathrm{Na}$ verdade, seguindo as regras de acentuação do português, as palavras em 
negrito deveriam ser pronunciadas como oxítonas, o que seria mais um equívoco. Entretanto, são palavras paroxítonas, em que a última sílaba é fraca, com exceção do "de", que é um monossílabo átono; portanto, grafam-se com "e" final: "disse", "hoje", "arrume". A ocorrência desse fenômeno em alguns verbos é bastante peculiar e esclarecedora, pois o emprego do " $\mathrm{e}$ " ou do " $\mathrm{i}$ " marca o tempo verbal, como em: "come"/"bebe"/"parte" (terceira pessoa do singular do presente do indicativo) e "comi"/"bebi"/"parti" (primeira pessoa do singular do pretérito perfeito do indicativo). Chama atenção ainda o fato de as palavras escritas de forma equivocada pelos estudantes serem bastante comuns, o que revela o seu baixo grau de letramento, mesmo estando no primeiro ano do ensino médio, ou seja, há pelo menos oito anos tendo aulas regulares da língua que utilizam todos os dias para interagir socialmente. Sobre esse fenômeno, contabilizamos 5 (cinco) momentos em que ele aparece, o que corresponde a 1,4\% dos dados analisados.

\subsubsection{Fenômeno da assimilaçáo}

A assimilação "é a força que tenta fazer com que dois sons diferentes, mas com algum parentesco, se tornem iguais, semelhantes" (BAGNO, 2006b, p. 77). A título de ilustração, vejamos esse fenômeno no exemplo abaixo:

[17] "No mundo atual pessoas estão consumino muito alcoo isso é bebidas alcolicas principalmente os jovens...”

Como se sabe, os fonemas /n/ e /d/ são linguodentais, o que justifica o "parentesco" a que se refere o linguista citado. Isso acontece mais precisamente na forma nominal do verbo no gerúndio, cuja terminação em português é "-ndo". Para o exemplo acima, dizemos que houve uma assimilação, uma vez que a forma culta seria "consumindo". Esse fenômeno tem se tornado cada vez mais frequente no português falado do Brasil, até mesmo entre as pessoas que têm um nível razoável de letramento. A supressão do fonema /d/ cria uma variação estigmatizada para a forma do gerúndio; por essa razão, torna-se interessante refletir sobre os aspectos relativos à escrita padrão, de modo que os estudantes não sejam privados do seu direito de se empoderarem linguisticamente para poderem melhorar sua escrita e, assim, vislumbrarem alguma forma de ascensão social. Este fenômeno ocorreu apenas 3 (três) vezes, o que representa $0,8 \%$ dos erros encontrados nos textos analisados.

\subsection{Irregularidades do sistema ortográfico}

Os chamados erros irregulares são aqueles que não se explicam por uma norma que possa ser aplicada; eles são desvios de uma convenção que nos foi meramente imposta, o que nos impossibilita de explicá-los através de regras, visto que muitas vezes estão ligados à etimologia das palavras. A consulta a fontes autorizadas - dicionários impressos ou virtuais, por exemplo - a observação atenta e cuidadosa, em textos bem escritos, e a memorização parecem ser boas alternativas para evitar esse tipo de erro. Como já frisou Morais (2012, p. 161), nesses casos, “o 
aluno vai ter que aprender memorizando, mas deve ter a oportunidade de refletir e tomar consciência de que precisa memorizar, porque ali não há regras". Vejamos a seguir os principais desvios dessa natureza constatados com a pesquisa.

\subsubsection{Fonema /s/}

O fragmento abaixo exemplifica a confusão que o escrevente faz quando precisa representar o fonema /s/ na escrita, em função das múltiplas possibilidades de notação gráfica possíveis dentro do sistema da língua.

[18] “... No país em que vivemos, uma vaga no Mercado de trabalho ceja la qual for e muito dificio, (...) poucos conseguem [emprego] e muitos procuram outros meios sobrevivençia como os agricultore e os vendedores inlegais. (...) Mas nos todos que estudamos temos um futuro melhor, com mas chanses de empregos melhores (...) Cada vez mas que agente isentiva um amigo ou familiar a ir pra escola e um ato de bondade para o futuro de cada um de nos"

Os termos destacados apresentam erros quanto à grafia para representar o fonema /s/, pois as palavras corretas, segundo a norma padrão da língua escrita, deveriam ser respectivamente: "seja", "sobrevivência", "chances" e "incentiva". Essa oscilação, que causa dúvida até em pessoas com alto nível de escolaridade e de letramento, acontece em virtude de haver uma concorrência entre vários grafemas para representar esse fonema, tal como as letras ou dígrafos "s", "c", "x", "ss", "sc", "sç", "z", "ç" e "xc". Urge explicitar que esse tipo de desvio ortográfico foi predominante nas produções textuais examinadas, totalizando 69 (sessenta e nove) ocorrências, o que corresponde a 19,3\% dos dados analisados.

\subsubsection{Fonema $/ z \mid$}

O fonema / z/ na língua portuguesa, de modo geral, ilustra outro caso recorrente de irregularidade do sistema ortográfico. Vejamos o excerto abaixo:

[19] "Na crize politica que hove no partido do PT onde foi descoberto e denunciado robos desvios de verbas enfim muitas injustiças e corrupção..."

O termo em negrito mostra mais um caso de irregularidade da língua, pois a representação do fonema / $z$ / - que também se dá por concorrência - pode ser feita por três letras: " $\mathrm{z}$ ", " $\mathrm{s}$ " e " $\mathrm{x}$ ". Nesses casos, o aluno se equivocou porque o próprio sistema da língua poderia admitir qualquer uma dessas representações; no entanto, a norma ortográfica, que é pura convenção, exige que a palavra seja grafada como "crise". Essa ocorrência também é reveladora de quão pouco esse estudante lê e pratica a escrita, por se tratar de palavra bastante comum nos usos corriqueiros da linguagem escrita. Por outro lado, identificamos dois casos em que a representação do fonema /z/ é passível de explicação:

[20] "Os bandidos estavam armados e drogados os elementos obrigaram as pessoas sairem do carro elas ficaram nervoza mas os bamdidos não machucaram ningem. (...) [Os bandidos] falou para a sua família que não se assustassem por que seria perigozo...” 
Os qualificadores "nervosa" e "perigoso" seguem uma regra que pode ser ensinada e o aluno poderá compreendê-la, ou seja, trata-se de um caso de regularidade morfológico-gramatical, em que adjetivo derivado de substantivo ("nervo", "perigo") e terminado em "-oso"/“-osa", se escreverá sempre com "s" nesse sufixo. Equívocos que envolveram o uso do fonema / $\mathrm{z} /$ foram encontrados em um número de 21 (vinte e uma) ocorrências, perfazendo um total de 5,9\% dos erros investigados.

\subsubsection{Emprego da letra " $x$ "}

Acerca do uso da letra " $x$ ", vejamos o seguinte problema:

[21] “... No verão a poeira emcomoda deicha as crianças gripadas...” (C2 Anexo VI)

O vocábulo destacado mostra a complexidade do emprego dessa letra, uma vez que ela pode representar qualquer um dos fonemas ou grupo de fonemas: $/ \check{\mathrm{s}} /, / \mathrm{z} /, / \mathrm{s} /, / \mathrm{ks} /$, dependendo da palavra. Por isso, o seu emprego não pode ser normatizado por uma regra específica. Isso está claro no exemplo acima, cuja escrita, segundo o padrão culto formal, deveria ser "deixa". Identificamos 04 (quatro) casos dessa natureza, correspondendo a 1,1\% do total de erros analisados.

\subsubsection{Fenômeno da monotongaçáo}

O fenômeno da monotongação pode ser definido, segundo Bagno (2006b, p. 88) como "dois sons que se transformam num só". Observemos o exemplo abaixo:

[22] “... Na crize política que hove no partido do PT onde foi descoberto e denuciado robos desvios de verbas enfim muitas injustiças e corrupção envolvendo a pessoa José Dirceu e outros"

Esse é um fenômeno fonético que inclusive já atingiu a língua falada no Brasil até mesmo em sua norma urbana culta, o qual consiste em suprimir a semivogal dos ditongos. Isso explica porque o aluno grafou "hove" em vez de "houve" e "robos" em vez de "roubos"; nesses casos, a semivogal /w/ foi suprimida. Os erros de ortografia correspondentes a esse fenômeno aconteceram poucas vezes, uma vez que identificamos 6 (seis) ocorrências, o que representa $1,7 \%$ dos dados analisados.

\subsubsection{Fenômeno da epêntese}

Para Henriques (2007, p. 23), a epêntese é um processo fonológico porque se refere às alterações a que estão sujeitos os fonemas, em virtude das combinações existentes entre eles na cadeia da fala por meio da adição de um novo fonema. Vejamos o exemplo que segue:

[23] “... partidos adiversarios criticaram o presidente Luís Inacio lula da silva..." 
Fica patente no exemplo destacado que esse fenômeno desfaz o encontro consonantal, acrescendo-se o fonema vocálico /i/, visto que a grafia culta exige a escrita "adversários". Na verdade, há de se convir que esse caso ilustra a força da oralidade sobre a escrita, pois, quando pronunciada, geralmente essa palavra soa de fato com o /i/ epentético, o que induz ao erro na escrita. Esse foi um fenômeno encontrado em pequena proporção com apenas 2 (duas) ocorrências, o que significa $0,6 \%$ dos dados analisados.

\subsubsection{Marcas da oralidade}

Para esta análise, escolhemos um exemplo representativo de como algumas marcas da oralidade são transferidas para a escrita quando o aluno produz seu texto. Vejamos:

[24] “... Que os seres humanos possam ver que isso [o desmatamento] está totalmente errado que eles estão fazendo, e pesa que da qui pra frente nós não possam mais ter florestas $\mathbf{p} /$ a nossa sobrevivência"

Apesar de fala e escrita não serem realidades dicotômicas, cada uma apresenta suas especificidades (MARCUSCHI, 2010). Diríamos que no momento da escritura esta é muito influenciada por aquela, principalmente quando se trata de escreventes que não têm muito contato com textos formais escritos. Nesse sentido, são inúmeros os casos em que as marcas da oralidade estão presentes nos textos produzidos pelos nossos alunos, as quais nem sempre são justificadas com base em regras, senão pela questão fonética ${ }^{5}$. Em [24], poderíamos explicar ao aluno os diferentes registros da língua, orientando-o que tal forma é mais adequada para o contexto informal, enquanto para uma situação mais formal ele terá que usar a forma "para", haja vista o gênero que está sendo produzido, seu suporte e seu auditório. A bem dizer, o "pra" é a norma típica da oralidade, mesmo em contextos de fala mais elaborada. Há no texto do estudante, ainda, uma influência da escrita informal sobre a escrita formal: o emprego de "p/" ("para") é comum nos usos coloquiais da escrita, especialmente em contextos de interação verbal nas redes sociais digitais. Frisamos que erros dessa natureza são frequentes; não é por acaso que foram identificadas 47 (quarenta e sete) ocorrências, as quais representam $13,2 \%$ dos dados investigados.

\subsubsection{Letras $\mathrm{E} / \mathrm{I} / \mathrm{O} / \mathrm{U}$ em sílabas átonas que não estáo no final das palavras}

Quanto ao emprego dessas letras em sílabas átonas que estão no início ou no meio das palavras, observemos o seguinte fragmento:

5 Cumpre lembrar, também, que alguns gêneros podem admitir a presença de marcas da oralidade, tal como a crônica. Em outros casos, o tom do texto escrito também pode se aproximar da língua falada, a exemplo da carta do leitor, dependendo do suporte midiático (NUNES, 2011). 
[25] "Num país como o nosso tem uma disputa muito grande, principalmente dos istudantes que procuram enpregos com carteira assinada. (...) seja em qualquer inprego"

As vogais das palavras destacadas não estão subordinadas a uma regra em particular; por conseguinte, trata-se de mais um caso de irregularidade do sistema ortográfico do português. Em [25], a vogal pretônica "i" deveria ser grafada com "e"; quando aparece em sílabas átonas que não estão no fim das palavras, o emprego dessa letra deixa dúvidas, porque na pronúncia aparece um /i/ como em "istudantes" ("estudantes") e "inprego" ("emprego"). Confusões no uso dessas letras apareceram de forma expressiva, com 25 (vinte e cinco) ocorrências, perfazendo $7 \%$ dos erros analisados.

\subsubsection{Emprego da letra " $h$ " no início de palavras}

Sobre esse fenômeno, vejamos o excerto abaixo:

[26] “... este trabalho vai ser muito bom para os jovens que estão amadorecendo agora e tem o desejo de ter um emprego fixo e onesto"

O uso da letra "h" no início de palavras é mais uma irregularidade do sistema gráfico do português. De fato, o "h" é letra, mas não é fonema, o que em parte justifica os equívocos relativos ao seu emprego ou não emprego. Uma razão para o uso dessa letra no início de algumas palavras tem motivação etimológica, posto que "nossa escrita é ainda diacronicamente motivada, isto é, em alguns casos só podemos explicar a representação ortográfica recorrendo à história da língua" (KATO, 2005, p. 19). Ora, talvez essa pista seja interessante para o pesquisador ou para o estudioso que se debruça sobre a evolução da língua. Todavia, sabemos que o falante e o escrevente simplesmente usam a língua sem refletir sobre sua história. Aliás, para o falante comum, pouco importa a história da língua. O exemplo dado em [26] reitera a arbitrariedade do emprego do "h" inicial, quando o aluno escreve "onesto" em vez de "honesto". De qualquer modo, há de se frisar que, embora não exista uma regra que ajude o estudante a compreendê-la, a palavra grafada sem o "h" inicial no texto não é esdrúxula, o que, em parte, leva a afirmar que o escrevente já a deveria ter memorizado. Sublinhamos que ao longo das análises realizadas esse tipo de erro ocorreu 10 (dez) vezes, o que equivale a 2,8\% dos dados analisados.

\subsubsection{Fonema /̌̌l}

No que diz respeito a esse fenômeno, observemos o que o estudante escreveu:

[27] “... Seu José abriu a janela e pessebeu que avia jente tentando derrubar a sua porta da cozia..."

A disputa das letras "g" e "j" para representar o fonema /ž/ causa dúvidas para quem escreve porque não há uma regra que se explique pelo contexto da palavra nem pela morfologia. Tem-se, como alternativa, internalizar por meio da observação e/ou memorização, visto que essa é uma palavra muito comum 
no léxico da língua. Esse fenômeno apareceu apenas uma vez nos cem textos analisados, o que corresponde a $0,3 \%$ dos erros analisados.

\section{Consideraçóes finais}

Constatamos que os erros ortográficos mais recorrentes nas produções analisadas têm a ver com: (i) a falta do hábito de leitura de textos, especificamente daqueles escritos no registro formal; (ii) a influência fonética, uma vez que os escreventes registram marcas da oralidade; e (iii) as lacunas deixadas pela escola ao longo dos anos, a qual nem sempre tem critérios definidos para o trabalho com a normatização ortográfica nas aulas de língua portuguesa. Todos esses fatores contribuem para as dificuldades nos usos das regularidades e irregularidades da convenção escrita.

De fato, chama atenção o fato de três dos cinco problemas mais recorrentes ("fenômeno da nasalização"; "ausência de 'r' no infinitivo"; "acentuação gráfica") serem erros regulares, ou seja, passíveis de serem compreendidos pelo aluno por meio de regras. Nesse ponto, deixou-se muito a desejar, desde o processo de alfabetização, pois, no nível que se encontram, tais alunos já não mais deveriam cometer tais erros com tanta frequência. Verificamos, também, que o erro prototípico em praticamente todas as produções dos estudantes é um caso de irregularidade ("o fonema /s/"); entretanto, muitas das palavras escritas de forma equivocada no que diz respeito ao emprego desse fonema são bastante comuns no léxico do português.

Assim sendo, postulamos que um ensino eficiente da ortografia perpassa necessariamente pelo conhecimento da sua natureza, bem como por uma visão da complexidade do sistema ortográfico, que é composto de regras que se explicam regularidades - e de convenções arbitrárias - irregularidades. Sem esse conhecimento mínimo, por parte do docente, fica difícil compreender os desvios ortográficos dos estudantes. Cumpre ressaltar, ainda, que a ortografia aqui é o objeto central da discussão; contudo, não podemos nos esquecer de que os estudantes apresentam problemas sérios em relação à organização textual-discursiva e à construção da argumentação nos gêneros do corpus da pesquisa. Portanto, cabe investigar esses problemas e procurar compreendê-los à luz dos letramentos desses estudantes.

Considerando a própria sala de aula como um laboratório de pesquisa, defendemos a postura de um professor que seja também pesquisador, objetivando uma atualização contínua para a transformação da sua prática pedagógica. A partir disso, ele poderá refletir sobre o seu fazer pedagógico em sala de aula, com o intuito de ajudar os alunos a construírem a sua competência textual-discursiva e a serem capazes de alcançar patamares mais elevados, tanto na vida acadêmica, quanto no mundo do trabalho. 


\section{Referências}

ANTUNES, I. Muito além da gramática: por um ensino de línguas sem pedras no caminho. São Paulo: Parábola Editorial, 2007.

BAGNO, M. Preconceito linguístico: o que é, como se faz. 47. ed. São Paulo: Edições Loyola, 2006 .

BAGNO, M. A língua de Eulália: novela sociolinguística. São Paulo: Contexto, 2006b.

BECHARA, E. Dicionário da língua portuguesa Evanildo Bechara. Rio de Janeiro: Nova Fronteira, 2011.

BRASIL. MINISTÉRIO DA EDUCAÇÃO E CULTURA. Parâmetros Curriculares

Nacionais: ensino médio - linguagens, códigos e suas tecnologias. Brasília: MEC/

SEMTEC, 2002.

COUTO, H. H. Fonologia e Fonologia do português. Brasília: Thesaurus, 1997. p. 5782.

FARACO, C. A. Escrita e alfabetização: características do sistema gráfico do português. 2. ed. São Paulo: Contexto, 1994.

HENRIQUES, C. C. A nova ortografia: o que muda com o acordo ortográfico. Rio de Janeiro: Elsevier, 2009.

HENRIQUES, C. C. Fonética, Fonologia e Ortografia. Rio de Janeiro: Elsevier, 2007.

INSTITUTO ANTÔNIO HOUAISS. Escrevendo pela nova ortografia: como usar as regras do novo acordo ortográfico da língua portuguesa. 3. ed. São Paulo: Publifolha, 2009.

KATO, M. A. No mundo da escrita: uma perspectiva psicolinguística. São Paulo: Ática, 2005.

MARCUSCHI, L. A. Da fala para a escrita: atividades de retextualização. 10. ed. São Paulo: Cortez, 2010.

MORAIS, A. G. Sistema de escrita alfabética. São Paulo: Melhoramentos, 2012.

MORAIS, A. G. Ortografia: ensinar e aprender. 5. ed. São Paulo: Ática, 2009.

MORAIS, A. G. Ortografia: este peculiar objeto de conhecimento. In: (Org.). $\mathbf{O}$ aprendizado da ortografia. 3. ed. Belo Horizonte: Autêntica, 2007. p. 7-19.

NORMAND, C. Saussure. São Paulo: Estação Liberdade, 2009.

NUNES, V. S. Condições de produção do discurso burocrático: prelúdios de uma análise. Entrepalavras, v. 5, n. 1, p. 47-58, jan./jun. 2015. Disponível em: < http://www. entrepalavras.ufc.br/revista/index.php/Revista/article/view/462/274> Acesso em: 19 jul. 2017. 
NUNES, V. S. Traços da oralidade no gênero carta do leitor. In: MELO, D. W.; SANTOS, M. F. O. (Org.). Retórica e Análise da Conversação: um encontro possível. Maceió: EDUFAL, 2011. p. 197-211.

POSSENTI, S. Sobre o ensino de português na escola. In: GERALDI, J. W. (Org.). O texto na sala de aula. 3. ed. São Paulo: Ática, 1999. p. 32-38.

PROENÇA FILHO, D. Guia prático da ortografia da língua portuguesa. Rio de Janeiro: Record, 2009.

ZORAYA, C.; LIMA, A. Corrigir ou avaliar redações: uma prática (im)positiva. In: XAVIER, Antônio Carlos (Org). O texto na escola: produção, leitura e avaliação. Recife: Ed. do Autor, 2007, p. 71-81. 